\title{
Long-term outcomes of stapled hemorrhoidopexy
}

\author{
Maciej Michalik ${ }^{1}$, Maciej Pawlak ${ }^{1}$, Maciej Bobowicz ${ }^{2}$, Mieczysław Witzling ${ }^{1}$ \\ 1Department of General and Vascular Surgery, Ceynowa Hospital, Wejherowo, Poland \\ 2Department of Surgical Oncology, Medical University of Gdansk, Poland
}

Videosurgery Miniinv 2014; 9 (1): 18-23 DOI: 10.5114/wiitm.2011.35784

\begin{abstract}
Introduction: Hemorrhoidal disease is one of the commonest anorectal disorders worldwide. Stapled hemorrhoidopexy $(\mathrm{SH})$ is a treatment modality associated with low postoperative pain and early mobilization.

Aim: To assess long-term outcomes after $\mathrm{SH}$.

Material and methods: All 326 patients who underwent SH in 1999-2003 were invited by mail to participate. For each patient we analyzed their medical records, and conducted a questionnaire survey and a digital rectal examination.

Results: Only 91 patients attended the final examination and the mean \pm SD follow-up time was $8.7 \pm 1.2$ years. Recurrences were diagnosed in one third of the 91 subjects. There were correlations between recurrences and: the duration of disease ( $p=0.047)$; female gender $(p=0.037)$; and childbirth (vaginal delivery) $(p=0.026)$. Sixty-seven patients (73.6\%) were satisfied with the outcomes. In the group of dissatisfied patients symptoms such as pain $(p=0.0001)$, burning $(p=0.0002)$ and itching $(p=0.014)$ were most common. Long-term outcomes were good with $75 \%$ and $88 \%$ reductions in pain sensation and severe and moderate hemorrhoidal bleeding. Pruritus, burning and discomfort resolved in more than $50 \%$ of patients. Flatus incontinence, fecal incontinence, or soiling occurred in $21 \%, 11 \%$, and $32 \%$ of patients.

Conclusions: Long-term results of stapled hemorrhoidopexy are satisfactory in most patients. The $36 \%$ recurrence rate correlates with the degree of hemorrhoidal prolapse before the operation, duration of the disease, female gender, and previous vaginal delivery.
\end{abstract}

Key words: stapled hemorrhoidopexy, hemorrhoids, anorectal surgery.

\section{Introduction}

Hemorrhoidal disease is one of the commonest anorectal disorders. Its prevalence in adults is estimated to be $5 \%$ worldwide, but the actual number of people suffering from the disease may be significantly higher as patients are often reluctant to seek medical help because of embarrassment or the fear of discomfort and pain associated with treatment. Some report that up to $90 \%$ of people may have hemorrhoidal symptoms at least once in their lifetime [1].
Internal hemorrhoids, i.e. above the dentate line, are classified into four grades according to the extent of prolapse [1-3]. Treatment depends on the degree of prolapse. First and second degree hemorrhoids are often successfully treated with conservative, non-surgical therapy. However, surgery is indicated for grade III and IV hemorrhoids. Surgical procedures include sclerotherapy, cryosurgery, infrared coagulation, rubber band ligation, and various modes of surgical excision. For many years the most widely used procedures were Morgan-Milligan and Ferguson techniques (with

Address for correspondence

Maciej Pawlak, Department of General and Vascular Surgery, Ceynowa Hospital, 10 Jagalskiego St, 84-200 Wejherowo, Poland,

phone: +48 501492 484, e-mail: maciek.pawlak@wp.pl 
or without modifications). Despite excellent results and low complication rates, these traditional surgical approaches are associated with severe postoperative pain due to removal of perianal skin and innervated anoderm below the dentate line [2, 3].

In 1998 Longo introduced a new surgical technique for the treatment of grade III and IV hemorrhoids. It uses a circular stapler to excise a circumferential band of excessive rectal mucosa and submucosa proximal to the dentate line. This procedure not only lifts the prolapsed hemorrhoidal tissue by removing the redundant mucosa, but also reduces the blood supply by stapling off the terminal branches of the superior hemorrhoidal artery [4]. Because this technique avoids interruption of the highly innervated anoderm, stapled hemorrhoidopexy $(\mathrm{SH})$ is associated with less postoperative pain and consequently earlier mobilization and return to work, than conventional hemorrhoidectomy [5]. The $\mathrm{SH}$ has been validated in several randomized, controlled trials with short-term follow-up $[5,6]$. Despite some obvious advantages, meta-analyses and systematic reviews give inconsistent results [6-9].

\section{Aim}

The aim of this study was to assess long-term outcomes after $\mathrm{SH}$ in a single institution.

\section{Material and methods}

All patients who underwent $\mathrm{SH}$ for hemorrhoids in our institution between January 1999 and December 2003 (326; 151 male, 175 female) were initially included in the study. All were invited to take part in three scheduled postoperative visits: 1 month after surgery, one in 2005 and one in 2010. Despite sending invitation letters to all patients and flexible appointment dates, only 91 patients attended the final examination.

We performed rectoscopy on each patient before surgery to establish stage of the disease and to eliminate any other pathology responsible for hemorrhoid-like symptoms. Surgery was carried out under local anesthesia on patients in either the lithotomy or prone jack-knife position. Local anesthesia was achieved by injecting lidocaine $0.5 \%$ into the anal verge and submucosa of the anal canal. General anesthesia was provided when required. A standardized surgical technique with a $33 \mathrm{~mm}$ Hemorrhoid Ethicon EndoSurgery ${ }^{\circledR}$ Circular Stapler (PPH01) was used in all cases.
All 91 patients filled in a questionnaire survey specifically designed for this study. It consisted of five parts: epidemiology, symptoms and the severity of the disease before surgery, the course of the operation and the early postoperative period, primary and long-term outcomes and the level of patients' satisfaction and subjective evaluation of the results.

Additional information was obtained from patients' medical records. Finally each patient underwent a digital rectal examination conducted by a physician. This assessed the hemorrhoid recurrence by assigning a grade, and recording the presence of skin tags and other factors such as fecal soiling and incontinence. The height of the staple line was controlled as well.

\section{Statistical analysis}

Statistical analyses were performed using the computer software Statistica 9.0, StatSoft, Inc. (2009). To assess whether variables were normally distributed we used the Shapiro-Wilk test. The $\chi^{2}$ test was used for the incidence characteristics. Value of $p$ below 0.05 was considered to be significant.

\section{Results}

\section{Demographics}

The study group consisted of 91 patients: 49 (53.8\%) male and 42 (46.2\%) female patients. The mean \pm SD age at the time of the final assessment was 55.7 \pm 12.4 years. Patient characteristics are shown in Table I. The mean \pm SD duration of symptoms before surgery was $12.2 \pm 11.1$ years.

\section{Symptoms}

The most common symptoms before and after surgery are summarized in Table II. Ninety percent of the women had given birth to at least one child (vaginal delivery), and more than half attributed their disease to childbirth.

\section{Surgical outcomes}

The mean operative time was $15 \mathrm{~min}$ and the mean \pm SD length of hospitalization was $2.7 \pm 1.0$ days. Time to return to work was, on average, $14 \pm 31.7$ days; $82 \%$ of patients returned to work in less than 2 weeks. The mean \pm SD follow-up time was $8.7 \pm 1.2$ years. Postoperative bleeding occurred in 
Table I. Patients' characteristics

\begin{tabular}{|c|c|c|}
\hline Variable & Number $(n=91)$ & Percentage \\
\hline \multicolumn{3}{|l|}{ Sex: } \\
\hline Male & 49 & 53.8 \\
\hline Female & 42 & 46.2 \\
\hline \multicolumn{3}{|c|}{ Grade of hemorrhoidal disease: } \\
\hline$\|$ & 9 & 9.9 \\
\hline III & 46 & 50.5 \\
\hline IV & 36 & 39.6 \\
\hline \multicolumn{3}{|l|}{ Preoperative treatment: } \\
\hline Non-operative therapy & 68 & 74.7 \\
\hline Rubber-band ligation & 4 & 4.4 \\
\hline Hemorrhoidectomy & 3 & 3.3 \\
\hline None & 16 & 17.6 \\
\hline
\end{tabular}

$9(10 \%)$ cases and further surgery was required in 3 patients. One patient needed 2 units of PRBC transfusion. On average the bleeding lasted 2.6 days. In 16 patients (17.8\%) severe pain occurred, lasting on average 7 days. Postoperative analgesics were only administered on demand. Additionally, transient urinary retention occurred in 16 patients with a mean duration of $12 \mathrm{~h}$.

Hemorrhoids recurred in one third of the subjects. Figure 1 shows the distribution of relapses in relation to the time at which they arose. There was a statistically significant correlation between recurrences and the duration of disease $(p=0.047)$, female gender $(p=0.037)$ and having given birth $(p=0.026)$ (Figure 2). Other complications and outcomes are listed in Table III.

\section{Satisfaction rate}

Sixty-seven of the patients (73.6\%) were satisfied with the outcome and 11 (12.1\%) were disappointed.

Table II. Preoperative and postoperative symptoms

\begin{tabular}{|c|c|c|c|c|c|c|}
\hline \multirow[t]{3}{*}{ Symptoms } & \multicolumn{2}{|c|}{ Preoperative symptoms } & \multicolumn{4}{|c|}{ Postoperative symptoms } \\
\hline & \multirow[t]{2}{*}{ Number } & \multirow[t]{2}{*}{ Percentage } & \multicolumn{2}{|c|}{ Early (30 days) } & \multicolumn{2}{|c|}{ Late (after 30 days) } \\
\hline & & & Number & Percentage & Number & Percentage \\
\hline \multicolumn{7}{|l|}{ Pain: } \\
\hline No or mild & 31 & 34.8 & 47 & 52.2 & 77 & 84.6 \\
\hline Moderate & 45 & 50.6 & 27 & 30.0 & 11 & 12.1 \\
\hline Severe & 13 & 14.6 & 16 & 17.8 & 3 & 3.3 \\
\hline \multicolumn{7}{|l|}{ Bleeding: } \\
\hline No & 11 & 12.2 & 74 & 82.2 & 61 & 67 \\
\hline Occasional & 21 & 23.3 & - & - & 23 & 25.3 \\
\hline Moderate & 24 & 26.7 & 7 & 7.8 & 5 & 5.5 \\
\hline Severe & 34 & 37.8 & 9 & 10 & 2 & 2.2 \\
\hline Pruritus & 62 & 69.7 & - & - & 30 & 33.3 \\
\hline Burning & 65 & 73 & - & - & 23 & 25.3 \\
\hline Discomfort & 84 & 94.4 & - & - & 36 & 39.6 \\
\hline \multicolumn{7}{|l|}{ Constipation: } \\
\hline Occasional & 19 & 21.6 & & & & \\
\hline Chronic & 24 & 27.3 & & & & \\
\hline
\end{tabular}




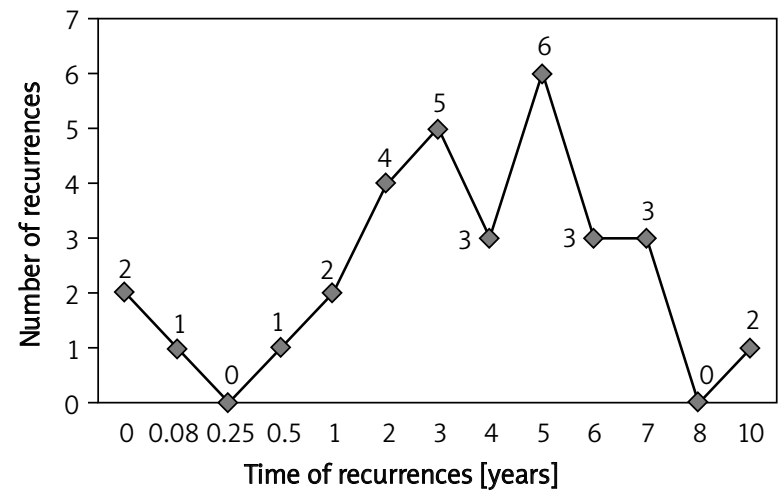

Figure 1. Distribution of recurrences over time

In 13 cases $(14.3 \%)$ the treatment did not fulfill patients' expectations at all. In the group of dissatisfied patients, symptoms such as pain ( $p=0.0001)$,

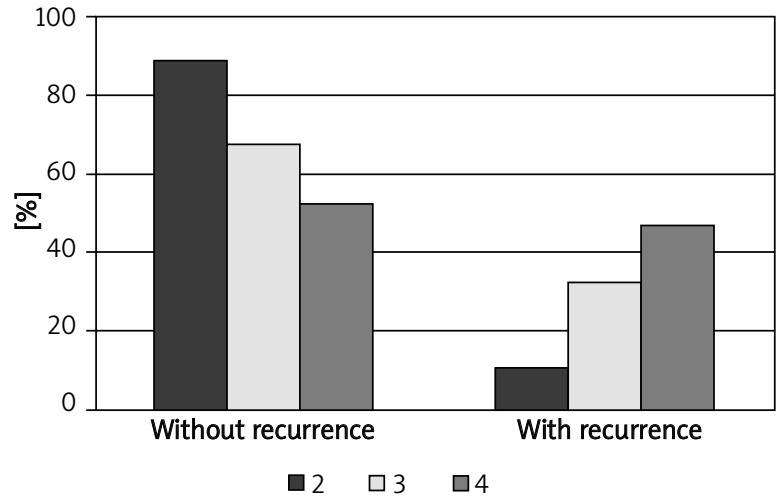

Figure 2. Number of recurrences in relation to pre-operative hemorrhoid prolapse level

burning ( $p=0.0002)$ and itching ( $p=0.014)$ occurred statistically more frequently than in satisfied patients.

Table III. Adverse events

\begin{tabular}{|c|c|c|c|c|}
\hline \multirow[t]{2}{*}{ Adverse events } & \multicolumn{2}{|c|}{ Early (30 days) } & \multicolumn{2}{|c|}{ Late (long-term) } \\
\hline & Number & Percentage & Number & Percentage \\
\hline Urinary retention & 16 & 18 & & \\
\hline Urgency & 15 & 16.5 & & \\
\hline Infections & 4 & 4.4 & & \\
\hline Anal fissure & 2 & 2.2 & & \\
\hline Staple line stenosis & 2 & 2.2 & & \\
\hline Mucous prolapse & 2 & 2.2 & & \\
\hline Failure of circular stapler & 1 & 1.1 & & \\
\hline Reoperations & 3 & 3.3 & 7 & 7.7 \\
\hline Recurrences: & & & 33 & 36.3 \\
\hline $1^{\text {st }}$ degree & & & 2 & 2.2 \\
\hline $2^{\text {nd }}$ degree & & & 14 & 15.4 \\
\hline $3^{\text {rd }}$ degree & & & 13 & 14.3 \\
\hline $4^{\text {th }}$ degree & & & 4 & 4.4 \\
\hline \multicolumn{5}{|l|}{ Residual skin tags: } \\
\hline Minor & & & 28 & 30.8 \\
\hline Major & & & 18 & 19.8 \\
\hline Flatus incontinence & & & 19 & 20.9 \\
\hline Fecal incontinence & & & 10 & 11 \\
\hline Soiling & & & 29 & 31.9 \\
\hline
\end{tabular}




\section{Discussion}

According to a meta-analysis by Giordano et al. SH offers several short-term advantages, such as reduced blood loss and postoperative pain with a faster recovery time and shortened hospital stay [10]. It also improves quality of life. The considerable increased risk of recurring hemorrhoidal prolapse should be weighed against these potential benefits and the patient should be involved in choosing the best treatment option.

Most patients treated with $\mathrm{SH}$ do not encounter any further symptoms and are discharged from the surgeon's care a few months after surgery. This is a serious obstacle if one attempts to assess longterm outcome. The response rate to our written invitations and the clinic attendance was only $28 \%$. This is similar to other studies assessing long-term outcomes of $\mathrm{SH}$ [11]. Kam et al. noted that responders tended to be those patients who had post-operative complications or recurrence of the disease, so that patients who were free of symptoms were under-represented. This is a source of selection bias and therefore one of the limitations of both their study [11] and ours.

Nevertheless, the outcomes of our study are similar to those reported by others [5-8]. The mean operative time of 15 min was short and comparable to other studies (range 9-24 min) in the meta-analysis by Laughlan et al. [7]. Length of hospitalization of 2.7 days was comparable with the results for MorganMilligan and Ferguson procedures in the same metaanalysis [7]. At the time our patients were treated our local health system enforced hospitalization times of around 3 days for small surgical procedures. This was done to obtain full reimbursement.

Long-term outcomes were good, with $75 \%$ reduction of pain in patients who had complained of severe or moderate pain before surgery and $88 \%$ reduction of episodes of severe and moderate hemorrhoidal bleeding. Pruritus, burning and discomfort also disappeared in more than half of the patients, which is slightly better than in some other studies [12].

Recurrence is a major issue associated with $\mathrm{SH}$. The systematic review by Laughlan et al. and the meta-analysis by Giordano et al. both showed that there is an increased risk of recurrence with $\mathrm{SH}$ compared with the Morgan-Milligan procedure, with odds ratios (ORs) ranging from 4.6 to 5.5 and incidence varying between 0 and $50 \%[7,10]$. The prolapse re- currence of $36 \%$ in our study is comparable with the findings summarized in a review by Kam et al. [11]. Interestingly, we found a statistically significant correlation between recurrences and the duration of the disease, female gender, and vaginal delivery. The recurrence rate also depended on the degree of hemorrhoidal prolapse before the operation. This raises the question of how patients were selected [13] and whether different techniques should be selected for some groups of patients $[14,15]$.

The apparent high rates of problems such as flatus and fecal incontinence and soiling although comparable with results by Kam et al. [11] could be the result of selection bias.

In our opinion there might be two possible solutions to deal with selection bias and the poor uptake rate in studies like ours. The first option is a follow-up system based on home visits. Despite the obvious benefit of increased participation rates it has some disadvantages including a high number of home visits during several years of study and the necessity to finance the work of additional staff involved whereas the study was financed solely by our department. It would also require a lot of long-distance travel as we provided SH procedures for patients from around the whole country. The second option is a follow-up performed over the phone but the obtained data would be incomplete due to the lack of rectal examination. Both proposed solutions assume that none of the patients would move to a new address or change the phone number. Due to the obvious disadvantages of both options we decided to send written invitations and to examine patients in the out-patient department.

\section{Conclusions}

The long-term results of SH are satisfactory in most patients. Patient dissatisfaction is usually related to symptoms such as pain, burning and itching. Recurrence rates of $36 \%$ correlate with the degree of hemorrhoidal prolapse before the operation and the duration of the disease, female gender, and childbirth by vaginal delivery.

\section{Acknowledgments}

The authors wish to thank Dr Joanna JassemBobowicz MD from the Medical University of Gdansk, Poland for her invaluable help in preparing the manuscript. 


\section{References}

1. Khubchandani I, Paonessa N, Azimuddin K (eds.). Surgical treatment of haemorrhoids. $2^{\text {nd }}$ ed. Springer 2009; 1-17.

2. Kaidar-Person O, Person B, Wexner SD. Haemorrhoidal disease: a comprehensive review. J Am Coll Surg 2007; 204: 102-17.

3. Halverson A. Haemorrhoids. Clin Colon Rectal Surg 2007; 20: 77-85.

4. Longo A. Treatment of haemorrhoids disease by reduction of mucosa and haemorrhoidal prolapse with a circular suturing device: a new procedure. In: Proceedings of The Sixth World Congress of Endoscopic Surgery. Bologna, Rome, Italy. Monduzzi Editore 1998; 777-84

5. Burch J, Epstein D, Sari AB, et al. Stapled haemorrhoidopexy for the treatment of haemorrhoids: a systematic review. Colorectal Dis 2009; 11: 233-43.

6. Lumb KJ, Colquhoun PH, Malthaner R, Jayaraman S. Stapled versus conventional surgery for hemorrhoids. Cochrane Database Syst Rev 2006; 4: CD005393.

7. Laughlan K, Jayne DG, Jackson D, et al. Stapled haemorrhoidopexy compared to Milligan-Morgan and Ferguson haemorrhoidectomy: a systematic review.Int J Colorectal Dis 2009; 24: 335-44.

8. Ganio E, Altomare DF, Milito G, et al. Long-term outcome of a multicentre randomized clinical trial of stapled haemorrhoidopexy versus Milligan-Morgan haemorrhoidectomy. $\mathrm{Br}$ J Surg 2007; 94: 1033-7.

9. Singer M, Abcarian H. Stapled haemorrhoidopexy: the argument for usage. Clin Colon Rectal Surg 2004; 17: 131-42.

10. Giordano P, Gravante G, Sorge R, et al. Long-term outcomes of stapled hemorrhoidopexyvs conventional hemorrhoidectomy: a meta-analysis of randomized controlled trials. Arch Surg 2009; 144: 266-72.

11. Kam MH, Ng KH, Lim JF, et al. Results of 7302 stapled haemorrhoidectomy operations in a single centre: a seven-year review and follow-up questionnaire survey. ANZ I Surg 2011; 81: 253-6.

12. Nyström PO, Qvist N, Raahave D, et al. Randomized clinical trial of symptom control after stapled anopexy or diathermy excision for haemorrhoid prolapse. Br J Surg 2010; 97: 167-76.

13. Jayne DG. Stapled haemorrhoidopexy for the treatment of haemorrhoids. Gastroenterol Clin Biol 2009; 33: 1021-3.

14. Chew MH, Tan WS, Eu KW. The use of CEEA 34 in stapled haemorrhoidectomy: suggested modifications in technique. World J Surg 2008; 32: 1160-1.

15. Bozdag AD, Yaman I, Derici H, et al. Comparison of a modified anoscope and the purse-string anoscope in stapled haemorrhoidopexy. World J Gastroenterol 2009; 15: 5573-8.

Received: 11.12.2012, accepted: 2.04.2013. 